\title{
The Principles of Teamwork and School Personnel Participation in the Administration of Liepaja City Comprehensive Schools
}

\author{
Inese Lusena - Ezera Liepaja \\ University, Latvia
}

\begin{abstract}
The successful management of the processes of economic change requires a new management approach, a new management philosophy and a paradigm change in thinking, thus the article views the issue of the performance of the team work and personnel participation in the achievement of the school's strategic aims. The empirical research data on school personnel participation, cooperation, communication, mutual trust and school culture of Liepaja city comprehensive schools has been analyzed in the context of this aspect, with particular attention being paid to the school personnel interpersonal relationship issue. The study involved personnel of Liepaja (Latvia) comprehensive schools, together 460 people. Study results revealed that in the schools involved in the study there is a high school culture and school personnel participation in school administration index, but at the same time the respondents' opinion discord concerning the school staff involvement in decision-making process, the assessment of school undertaking, and involvement in the design of school development plans. Differences in school staff opinions have also been found on the issue of cooperation at school. The study found a correlation between the school personnel mutual relationship index and the school personnel participation in school administration index, as well as school type correlation with the teamwork principles indices, school personnel participation in school administration index, school culture and school personnel mutual relationship significance index.
\end{abstract}

\section{Introduction}

The economic situation in Latvia and the world, reform of regions in Latvia and the declining number of students in the context of the increasing amount of information and knowledge, puts forward high demands for Latvian educational institutions that are characterized by competitiveness and the ability to integrate innovatively into the surrounding environment and is targeted towards the realization of sustainable development. Sustainable development of education during the change processes in all European Union Member States is regarded as one of the highest political goals. This goal requires such school management approach which, in result of successful implementation, leads to the establishment of the environment that encourages formation of a unified school personnel future vision on the work of the educational institution.

In today 's complex and dynamic world a single person or a couple of persons cannot manage everything. No leader, institution or nation can exist or lead without the support or involvement of others; the same applies to education as well. [2] Management activities should not be placed in one individual's hands, but rather the contrary - they should be shared both by teams and employees. [1] According to Goleman [3] this means that any person in one way or other would act as a leader. School personnel involvement in the management of educational institutions requires a management approach based on trust, cooperation, communication and cultural development and improvement, which in turn implies changes in the school strategy, culture, tasks and work organization. [2] The above mentioned points show the need to build a school environment that focuses on constructive debates, differences of views, goal and task interactions. [4;5;6] Already twenty-five years ago, Wynn and Guditus [7] found that an educational institution will gain noticeable benefit only if it is supported by a structure model which encourages maximum participation along with the appropriate cultural context which promotes collaboration.

\section{Research Methodology}

To determine whether the educational institutions focus on sustainable development, involving school 
personnel in school administration process and applying the principles of teamwork, an empirical study was conducted in Liepaja city comprehensive schools, surveying the school administration (principal and deputies), teachers and other school staff (support staff, librarians, methodologists, technical staff), totalling 460 survey respondents. Work with human resources is related to the formation of organizational culture and dealing with relationship issues, thus in addition to the school personnel participation and teamwork principles, the study seeks to examine the school culture and school staff mutual relationships and their significance level.

The study involved 16 Liepaja city comprehensive schools: 2 elementary, 4 primary, 10 secondary schools. The study was conducted from May 2007 till January 2009, including data collection, data processing and analysis of survey results.

In order to carry out the research a questionnaire was designed in which the respondents had to assess after the Likert scale:

- collaboration between school personnel from the "excellent" to "unsatisfactory";

- allegations about the involvement of school personnel in school management, communication and mutual trust - from "completely agree" to "completely disagree";

- interpersonal relations between the school personnel - from the "friendly, open" to "tense, competitive" relations;

- the importance of interpersonal relations of school personnel - from "very important" to "not important".

To clarify the school staff involvement in the assessment of school undertaking and involvement in the design school development plans, as well as to find out the parties involved in the decision-making process at school, questions were developed in the nominal measurement scale.

The questionnaire reliability testing was done, determining the Cronbach's Alpha coefficient of the whole questionnaire. A high poll alpha coefficient $(\alpha=$ $0.94)$ was obtained. The number of questions in the questionnaire was reduced using the index method. The indices were created by combining a number of questions along thematic groups, and compared according to the average values. The average value was determined by creating one measurement scale (from the most positive to the most negative). For each group of questions included in the index Cronbach's Alpha coefficient was determined. The indices were calculated as the average value of all the questions of thematic group which the respondents had answered. Afterwards the border values were found which led to the creation of the following indices with 3 qualities (low, medium or high index):
- Team-work principle Indices: School Personnel Mutual Cooperation Index (SPMCI) $(\alpha=0.65)$, the School Personnel Interpersonal Communication Index (SPICI) $(\alpha=0.82)$ and the School Personnel Mutual Trust Index (SPMTI) $(\alpha=0,78)$;

- School Personnel Participation in school administration Index (SPPsaI) $(\alpha=0.71)$;

- School Culture Index (SCI) $(\alpha=0.78)$;

- School Personnel Interpersonal Relations Index (SPIRI) $(\alpha=0.77)$;

- School Personnel Interpersonal Relations Significance Index (SPIRSI) $(\alpha=0.83)$.

To clarify the team-work principle, the personnel interpersonal relations and school culture inter-relation with the school personnel participation in the school administration and school type Spearman's rank correlation coefficient was used because the index ranking scales are on a rank scale; besides, the empirical distribution does not match the normal distribution, because according to the KolmogorovSmirnov Test $p$ value $<0.05$.

\subsection{Respondent characteristics}

It is self-evident that, in this study, the teachers are the most represented group of posts $(81.7 \%)$, school administration, together account for $10.6 \%$ of respondents, while $7.6 \%$ are other school staff. The schools involved in the study are mostly administrated by principals between the ages of 41 to 50 years $(41.7 \%)$. Teachers mainly represent the age group from 31 to 50 years (from 31 to 40 years $-27.9 \%$, from 41 50 years $33.5 \%$ ), while the other school staff make the largest proportion of the age category from 51 to 60 years $(31.4 \%)$. The average teaching experience for teachers / school administration and the average school staff length of service at school is 19.73 years. The average length of experience of school administration in managerial position is 9.69 years.

\subsection{Analysis of research results}

The summary of the created indices in Table 1 reveals that the city of Liepaja comprehensive schools have a high personnel participation in the administration of schools (SPPsaI), the personnel mutual trust (SPMTI), personnel communication (SPICI), school culture (SCI) and personnel interpersonal relations (SPIRI) index. The study also indicated high $(79,5 \%)$ school personnel interpersonal relations significance index (SPIRSI) (see Table 1). A diverse assessment was given about the personnel mutual cooperation. Moderate $(50.5 \%)$ and high (48.6\%) SPMCI were in almost equal levels (see Table $1)$. 
Taking into account the gained diverse SPMCI indicators shown in Table 1, it seemed important to ascertain whether the SPMCI is statistically significantly different in the position group of the respondents: among teachers, school staff, the school deputies and school principals. After comparing the results of four groups making use of the Kruskal Wallis Test, it can be concluded that there is a statistically significant difference in school personnel's opinions about the level of the school personnel mutual cooperation $(\mathrm{SPMCI})$ at school $(\mathrm{p}=0.033<0.05)$ (Table 1).

Table 1. Indicators of the Created Indices

\begin{tabular}{|lrrc|}
\hline Index level & \multicolumn{1}{c}{ low } & medium & high \\
\cline { 2 - 4 } Index & $\begin{array}{r}\text { Row Valid } \\
\mathrm{N} \%\end{array}$ & $\begin{array}{r}\text { Row Valid } \\
\mathrm{N} \%\end{array}$ & $\begin{array}{c}\text { Row Valid N } \\
\%\end{array}$ \\
\hline SPPsal &, $4 \%$ & $8,6 \%$ & $90,9 \%$ \\
SPMCI &, $9 \%$ & $50,5 \%$ & $48,6 \%$ \\
SPMTI &, $7 \%$ & $20,0 \%$ & $79,3 \%$ \\
SPICI &, $4 \%$ & $13,2 \%$ & $86,3 \%$ \\
SCI &, $0 \%$ & $7,2 \%$ & $92,8 \%$ \\
SPIRI & $1,1 \%$ & $15,5 \%$ & $83,4 \%$ \\
SPIRSI & $2,0 \%$ & $18,5 \%$ & $79,5 \%$ \\
\hline
\end{tabular}

In addition, it was discovered that there is also a statistically considerable difference in school personnel's opinions about the level of significance of interpersonal relations (SPIRSI) at school $(p=0.021<$ 0.05) (Table 2).

After setting up SPMCI and conducting the cross tabulation of the respondent positions, it was found that the divergent views on mutual cooperation of school personnel are most evident in the teacher group (Table 3). The average (49.2\%) and high (49.7\%) SPMCI are almost at equal levels, while differences in views on the significance of the school personnel interpersonal relations (SPIRSI) are evident among other school staff (Table 3).

The results of the correlation analysis between the school personnel participation in school administration index (SPPsaI) and school personnel mutual cooperation index (SPMCI), the school personnel interpersonal communication index (SPICI), the school personnel mutual trust index (SPMTI), the school culture index (SCI) and the school personnel interpersonal relations index (SPIRI) and their significance index (SPIRSI) are shown in Table 4.

Table 2. Kruskal Wallis Test Indicators in the Group of Respondent Job Position

\begin{tabular}{|c|c|c|c|}
\hline \multicolumn{4}{|c|}{ Test Statistics $^{a, b}$} \\
\hline & Chi- & df & "Asymp. Sig. \\
\hline SPPsal & 5,272 & 3 & ,153 \\
\hline SPMCI & 8,752 & 3 & ,033 \\
\hline SPMTI & 4,008 & 3 & ,261 \\
\hline SPICl & 5,866 & 3 & 118 \\
\hline $\mathrm{SCl}$ & 3,142 & 3 & ,370 \\
\hline SPIRI & 3,242 & 3 & ,356 \\
\hline SPIRSI & 9,706 & 3 &, 021 \\
\hline \multicolumn{4}{|c|}{ a. Kruskal Wallis Test } \\
\hline
\end{tabular}


Table 3. Cross tabulation of School Personnel Interpersonal Cooperation Index, Interpersonal Relations Significance Index and Respondent Job Position

\begin{tabular}{|c|c|c|c|c|c|}
\hline & & \multicolumn{4}{|c|}{ Respondent Job Position } \\
\hline & & teacher & $\begin{array}{c}\text { school } \\
\text { principal }\end{array}$ & $\begin{array}{c}\text { deputy } \\
\text { principal }\end{array}$ & school worker \\
\hline Index & Index level & $\begin{array}{c}\text { Column Valid } \\
\mathrm{N} \%\end{array}$ & $\begin{array}{c}\text { Column Valid } \\
\mathrm{N} \%\end{array}$ & $\begin{array}{c}\text { Column Valid } \\
\mathrm{N} \%\end{array}$ & $\begin{array}{c}\text { Column Valid } \\
\mathrm{N} \%\end{array}$ \\
\hline \multirow[t]{3}{*}{ SPMCl } & low & $1,1 \%$ &, $0 \%$ &, $0 \%$ &, $0 \%$ \\
\hline & medium & $49,2 \%$ & $66,7 \%$ & $38,9 \%$ & $71,4 \%$ \\
\hline & high & $49,7 \%$ & $33,3 \%$ & $61,1 \%$ & $28,6 \%$ \\
\hline \multirow[t]{3}{*}{ SPIRSI } & low & $1,9 \%$ &, $0 \%$ &, $0 \%$ & $5,7 \%$ \\
\hline & medium & $21,1 \%$ &, $0 \%$ & $5,4 \%$ & $11,4 \%$ \\
\hline & high & $77,1 \%$ & $100,0 \%$ & $94,6 \%$ & $82,9 \%$ \\
\hline
\end{tabular}

Table 4. Interrelation between the School Personnel Participation (SPPsaI) and Team-work Principles, School Culture (SCI) and School Personnel Interpersonal Relations (SPIRI)

\begin{tabular}{|c|c|c|c|c|c|c|c|c|}
\hline & & & SPMCI & SPMTI & SPICI & $\mathrm{SCl}$ & SPIRI & SPIRSI \\
\hline \multirow[t]{3}{*}{$\begin{array}{l}\text { Spearman's } \\
\text { rho }\end{array}$} & SPPsal & $\begin{array}{l}\text { Correlation } \\
\text { Coefficient }\end{array}$ &, $239^{\star *}$ &, $369^{\star \star}$ &, $523^{\star \star}$ &, $532^{* *}$ &, $259^{\star \star}$ & $274^{\star \star}$ \\
\hline & & Sig. (2-tailed) & ,000 & ,000 & ,000 & ,000 & ,000 & ,000 \\
\hline & & $\mathrm{N}$ & 450 & 451 & 446 & 450 & 444 & 450 \\
\hline
\end{tabular}

The obtained correlation results show that the relationship between the school personnel participation in school administration index (SPPsaI) is essential among all the team-work principle indices, as well as school culture index (SCI) and the school personnel interpersonal relations (SPIRI) and their significance (SPIRSI) index.

The interrelations between the indices are testified by all six correlations that are statistically significant at a confidence level of 0.01 . All correlations are positive, hence, with $99 \%$ probability it can be asserted the higher the cross-staff communication, cooperation, trust, interpersonal relations, relations significance and school culture index, the higher is the school personnel participation in school administration index.

Indices of school type grouping were also analyzed. Making the comparison in three groups (elementary, primary and secondary school), using the Kruskal Wallis Test, it was found that there is a statistically significant difference among the indices of elementary, primary and secondary schools: SPMCI $\mathrm{p}=0.000<$ 0.05 ; SPMTI $\mathrm{p}=0.000<0.05$; SPICI $\mathrm{p}=0.001<$ 0.05 ; school personnel participation in school administration index (SPPsaI) $\mathrm{p}=0.023<0.05$; school culture index $(\mathrm{SCI}) \mathrm{p}=0.041<0.05$ and school personnel interpersonal relationship significance index (SPIRSI) $\mathrm{p}=0.026<0.05$. A statistically significant difference in the school type group was not recognized among school personnel interpersonal relationship index (SPIRI) figures, since $\mathrm{p}=0.451>0.05$ (Table 5)

Table 5. Kruskal Wallis Test results

\begin{tabular}{|l|r|r|r|}
\hline \multicolumn{5}{|c|}{ Test Statistics $^{\text {a,b }}$} \\
\hline & Chi-square & df & Asymp. Sig. \\
\hline SPPsal & 7,570 & 2 &, 023 \\
\hline SPMCI & 18,702 & 2 &, 000 \\
\hline SPMTI & 19,893 & 2 &, 000 \\
\hline SPICI & 13,494 & 2 &, 001 \\
\hline SCI & 6,399 & 2 &, 041 \\
\hline SPIRI & 1,594 & 2 &, 451 \\
\hline SPIRSI & 7,326 & 2 &, 026 \\
\hline a. Kruskal Wallis Test & \multicolumn{3}{l}{} \\
\hline b. Grouping Variable: School type \\
\hline
\end{tabular}

The comparative analysis of indices and school type group reveals that the indices are the most distinct in the elementary school group, since the highest high and the lowest average teamwork principles indices, school personnel participation in school administration index (SPPsaI), school culture index (SCI) and school personnel interpersonal relationship significance index (SPIRSI) indicators are formed mainly by the elementary school respondents (Figure 1). The study 
results also show that the indices with the threshold "low" are present only in primary and secondary school group. This particular indicator does not exist in the elementary school group.

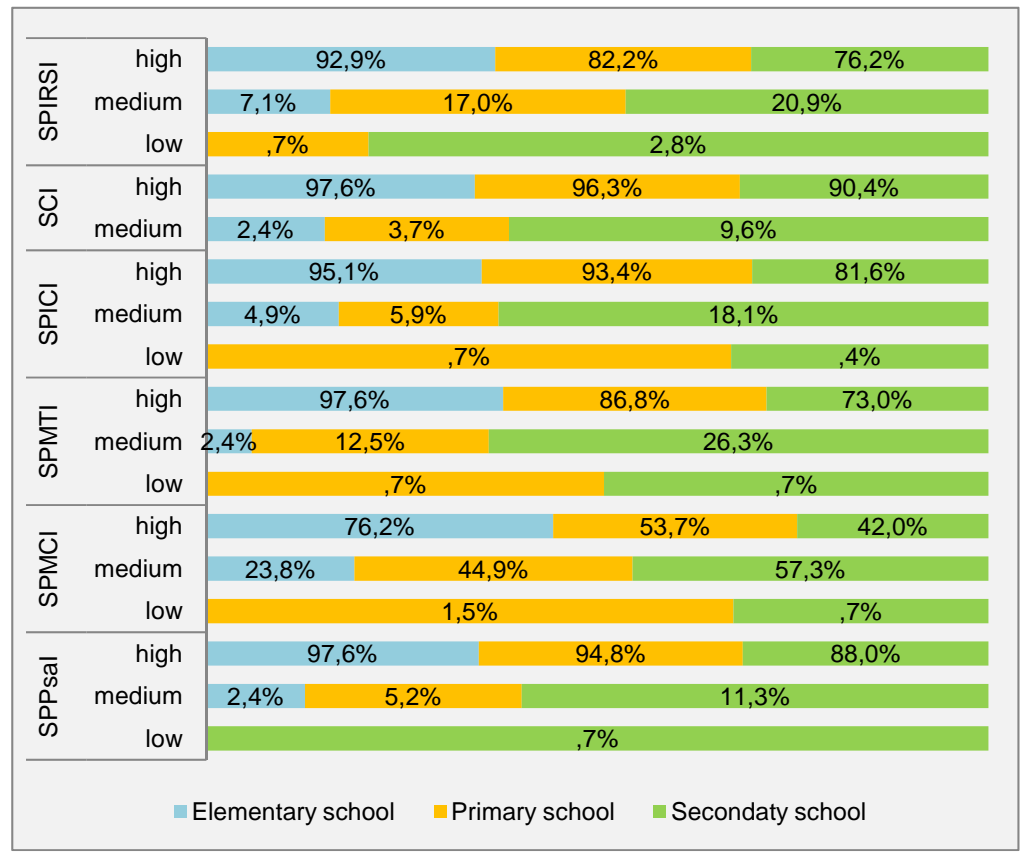

Figure 1. Created indices in school type grouping

Comparing the results shown in Figure 1, it can be seen that the teamwork principles indices, school personnel participation in school administration index (SPPsaI), school culture index (SCI) and school personnel interpersonal relationship significance index (SPIRSI) in school type group create a slight tendency - the smaller the school, the higher becomes the teamwork principles index, SPPsaI, SCI and SPIRSI index level. This trend is evident when comparing the school personnel mutual trust index (SPMTI) figures, where a high average SPMUTI index indicator percentage proportion - $26.3 \%$ in secondary school group gradually decreases to $2.4 \%$ in elementary school group, while a low high SPMTI index indicator percentage proportion - $73 \%$ in secondary school group gradually increases to $97.6 \%$ in elementary school group (Figure 1). The same trend is apparent also in indicators of other indices in secondary school, primary school and elementary school group. The discovered trend suggests a correlation among school type and teamwork principles index, school personnel participation in school administration index (SPPsaI), school culture index (SCI) and school personnel interpersonal relationship significance index
(SPIRSI), subsequently a correlation analysis was carried out. The correlation analysis results between the school type group and the correlation of above mentioned indices can be seen in Table 6. Despite the fact that correlation coefficients of school type group and indices presented in Table 6 are low, a statistically significant correlation between these variables, however, exists. Teamwork principles index (SPMCI, SPMTI, and SPICI), school personnel participation in school administration index (SPPsaI) and school type group correlations are statistically significant at 0.01 validity level (Table 6.) The correlation is negative, thus with $99 \%$ probability it can be asserted that the smaller the school, the higher becomes the teamwork principles index and the school personnel participation in school management index (SPIsaI) level. School culture index (SCI), school personnel interpersonal relationship significance index (SPIRSI) and school type group correlation is statistically significant at 0.05 validity level (Table 6.) The correlation is negative, therefore with $95 \%$ probability it can be affirmed that the smaller the school, the higher becomes school culture index (SCI) and school personnel interpersonal relationship significance index (SPIRSI) level. 
Table 6. Correlation results: the school type and teamwork principles index, the school personnel participation in school administration (SPPsaI), school culture (SCI), school personnel interpersonal relationship (SPIRI) and their significance (SPIRSI) index correlations

\begin{tabular}{|c|c|c|c|}
\hline \multirow{2}{*}{ Spearman's rho } & & & School type \\
\hline & \multirow[t]{3}{*}{ SPPsal } & Correlation Coefficient &,$- 130^{\text {** }}$ \\
\hline & & Sig. (2-tailed) & ,006 \\
\hline & & $\mathrm{N}$ & 451 \\
\hline & \multirow[t]{3}{*}{ SPMCl } & Correlation Coefficient &,$- 183^{\text {*x }}$ \\
\hline & & Sig. (2-tailed) & ,000 \\
\hline & & $\mathrm{N}$ & 459 \\
\hline & \multirow[t]{3}{*}{ SPMTI } & Correlation Coefficient &,$- 206^{\text {*x }}$ \\
\hline & & Sig. (2-tailed) & ,000 \\
\hline & & $\mathrm{N}$ & 459 \\
\hline & \multirow[t]{3}{*}{$\mathrm{SPICl}$} & Correlation Coefficient &,$- 171^{\star x}$ \\
\hline & & Sig. (2-tailed) &, 000 \\
\hline & & $\mathrm{N}$ & 454 \\
\hline & \multirow[t]{3}{*}{$\mathrm{SCl}$} & Correlation Coefficient &,$- 118^{*}$ \\
\hline & & Sig. (2-tailed) & ,012 \\
\hline & & $\mathrm{N}$ & 457 \\
\hline & \multirow[t]{3}{*}{ SPIRI } & Correlation Coefficient &,- 059 \\
\hline & & Sig. (2-tailed) & ,212 \\
\hline & & $\mathrm{N}$ & 453 \\
\hline & \multirow[t]{3}{*}{ SPIRSI } & Correlation Coefficient &,$- 118^{*}$ \\
\hline & & Sig. (2-tailed) &, 012 \\
\hline & & $\mathrm{N}$ & 459 \\
\hline \multicolumn{4}{|c|}{$\begin{array}{l}{ }^{* *} \text {. Correlation is significant at the } 0.01 \text { level (2-tailed). } \\
\star \text { *. Correlation is significant at the } 0.05 \text { level (2-tailed). }\end{array}$} \\
\hline & & 5 level (2-tailed). & \\
\hline
\end{tabular}

The study revealed that there is a high school personnel participation in school administration index (SPPsaI) in Liepaja city comprehensive schools, but a different situation was found while analyzing the results of the school staff involvement in the design of school development plans, in the assessment of school undertaking and decision-making.

The majority of survey respondents $(59.7 \%)$ think that school staff is involved in the assessment of school undertaking, while $32.1 \%$ of employees of Liepaja city comprehensive schools admit that the school staff involvement in the assessment of school undertaking is not carried out as a regular activity (Figure 2). The situation is similar with regard to staff involvement in the design of school development plans: only $40.6 \%$ of surveyed teachers, school workers and school leaders of Liepaja city comprehensive schools could assert that the entire school staff is involved in the design of school development plans, $32.4 \%$ of respondents believe that only school teaching staff are involved in the design of school development plans, while one fifth part $(20 \%)$ of the respondents are categorical, indicating that the design of school development plans is neither teachers' nor the school workers' duty (Figure 2. ) The respondents' views also differ on the issue of staff involvement in important decisionmaking, as there is no consensus whether the entire school staff $(33.9 \%)$ or only teachers $(37.4 \%)$ are involved in decision-making at school. $10.9 \%$ of respondents indicated that the decision-making process in their schools is implemented in a different way, not like offered in the questionnaire options.

Basically, the results reflected in Figure 2. are inconsistent with the school personnel participation in school administration index (SPPsaI) indicators: if $90.9 \%$ of Liepaja city comprehensive schools have a high SPPsaI (Table 1), it is self-evident that the results of school staff involvement in the assessment of school undertaking, participation in the design of school development plans and decision-making should be much higher.

\section{Conclusions}

Despite the high Liepaja city comprehensive school personnel interpersonal communication, trust, interpersonal relations, school culture and personnel participation in school administration index, the school personnel mutual cooperation needs the greatest improvement. This may be done by facilitating the interaction among school personnel and increasing the understanding of its necessity for school aim achievement.

The research proved that building better cooperation, communication and trust, as well as establishing better school culture, increases the level of school personnel involvement and participation in school management processes. 


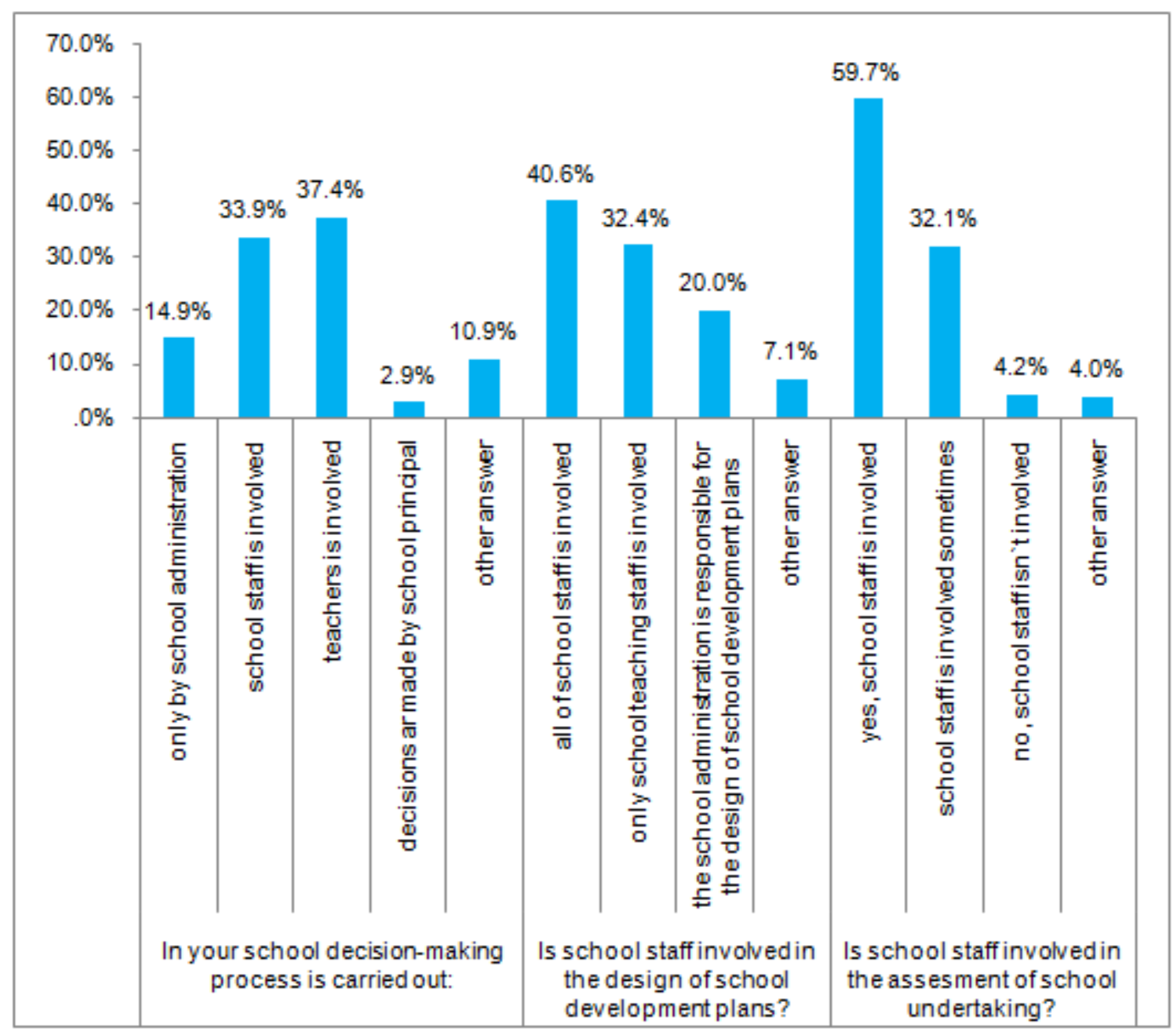

Figure 2. The school staff involvement in decision-making, in the design of school development plans and in the assessment of school undertaking

School personnel interpersonal relationships are related to personnel participation in school administration, therefore it is reasonable to assume that the better relationships, the greater opportunity for the school staff to participate in major decision making and to take on responsibility for its implementation, as also provide them with the chance to fulfil and assert themselves as leaders at school not only in their professional fields, but also outside them. The process of school personnel involvement in school administration should not be based on interpersonal relations, but on the assessment of each school staff member's knowledge, skills and willingness to invest their knowledge and skills in the development of sustainable school. The study involved teachers, school workers and school principals of Liepaja city comprehensive schools. Analyzing the results of the study on the significance of school personnel interpersonal relationships and staff cooperation, it was clarified that on both issues the opinions of school leadership and teachers/school employees differ. The results obtained suggest that school leaders have a higher opinion of the significance of school staff relationships in their educational institutions than the teachers and school workers. As regards the school staff cooperation index results, the author concludes that there are diverse opinions between teachers and school workers, the deputy principals and school workers.

The implementation of sustainable development is linked to the formation of a school personnel common future vision of educational institution. This in turn implies the need to involve personnel in important decision-making process, in the design of school development plans and in the assessment of school undertaking. Despite the high school personnel 
participation in school administration index, the respondents' views on school personnel involvement in the assessment of school undertaking and in the design of school development documents, however, are less unambiguous. Difference in opinions of the surveyed employees of Liepaja city comprehensive schools on these issues suggests that every teacher, school worker and leaders has their own idea and criteria whether the person is/is being involved in the management of school or not.

The results of comparative analysis of school type and created indices suggest that teamwork principles indices, school personnel participation, school culture and school personnel interpersonal relationship significance index level is higher in elementary schools than primary and secondary schools.

Following the findings of the study, it can be concluded that, overall, Liepaja city comprehensive schools undertaking are directed to school sustainable development because schools are managed with the help of teamwork principles, as well as school staff has an opportunity to participate in the administration of the educational institution.

\section{References}

[1] A., Storey, "The problem of distributed leadership in schools", School leadership \& Management, Routledge, 2004, pp. 249-265.

[2] D. Celma, I. Lusena - Ezera, "Teamwork - the basis for successful work an organization", Humanities and Social Sciences: Latvia, Institute of Economics, Latvian Academy of Sciences, Ltd., Riga, 2007, pp. 105-123.

[3] Goleman, D., Boyatzis R., Mckee A., The New Leaders: Transforming the Art of Leadership into the science of results, Little Brown, London, 2002.

[4] J., Vesey, „Team collaboration leads to sense of community", NASSP Bulletin, SAGE Publications, 1996, pp. 31-34.

[5] J.E. Bono, T.A. Judge, "Self concordance at work: Toward understanding the motivational effects of transformational leaders", Academy of Management Journal, Academy of Management, 2003, pp.554-571.

[6] S.T., Wineburg, „Eliot, collaboration and the quandaries of assessment in a rapidly changing world", Phi Delta Kappan, Phi Delta Kappa International, Inc., 1997, pp. 5963.

[7] Wynn R., Guditus C. Team management: leadership by consensus. Charles E. Merrill, Columbus, 1984. 